Ann. Zootech., Ig69, 18 (4), 399-405.

\title{
EVALUATION OF VARIOUS METHODS OF MEASURING EGG SHELL QUALITY
}

\author{
N. SNAPIR and M. PEREK \\ Department of Poultry Science and Animal Hygiene, \\ Facully of Agriculture, Hebrew University of Jerusalem Rehovoth, Israël
}

SOMMAIRE

Le poids relatif de la coquille à l'œuf entier a été comparé au poids par unité de surface chez des œufs pondus par des poules de race S. C. White I.eghorn de deux âges différents. Les œufs pesaient $53, \mathrm{I} \pm 0,7 \mathrm{~g}$ et $64,2 \pm 0,4 \mathrm{~g}$ suivant qu'il s'agissait de pondeuses de ro ou 22 mois. Une corrélation hautement significative entre les 2 " méthodes" et pour les deux groupes d'animaux a été obtenue.

Étant donné la corrélation significative existant entre le poids relatif de la coquille à l'œuf entier et la taille de celui-ci, il est suggéré d'utiliser ce critère dans l'évaluation de la qualité de la coquille d'œuf, mais ceci uniquement lorsqu'on a affaire à des œufs de poids similaire.

Lors d'une seconde expérience, la résistance à la force de casse, l'épaisseur et le poids de la coquille par unité de surface ont été comparés pour des œufs $(55,6 \pm \mathrm{I}, 4 \mathrm{~g})$ provenant de pondeuses âgées de neuf mois. Les corrélations trouvées entre ces trois paramètres sont hautement significatives. La méthode utilisant le poids de la coquille par unité de surface comme critère de détermination de la qualité de la coquille semble être la meilleure et c'est elle qui sera choisie dans les études ultérieures.

\section{INTRODUCTION}

Various methods for measuring egg-shell quality have been suggested by different workers : specific gravity (OLsson, I934), shell deformability (ScHOoRL and Bokrsma, I963), breaking strength (RomanofF, I929), shell thickness (Morgan, I932), shcll wcight per unit of surface area (TYIER and GEAKE, I96I) and percentage of shell from whole egg weight (MORGAN, I932). Some correlations have been shown to exist between these methods (BAKER and CUR'TIS, I958 ; TYLER and GEAKE, I96I ; 
Schoorl, and Boersma, I963; Fry et al., I963; MARKS and KrNney, I964; CaRTer, $a$ and $b$, Ig68; TUNG et $a l .$, I968).

As early as I940, ASmUNDSON and BAKER sharply criticised the method of measuring percentage of shell as a means of assessing egg shell quality. TYLER and GEAKE (I96r), in a critical analysis of different methods, came to the conclusion that this method should be eliminated because of its inaccuracy.

In the present work some of the common methods mentioned have been reevaluated for the purpose of selecting an easy and reliable method to determine egg-shell quality; it is part of a larger study on physiological factors related to egg-shell formation. Two experiments were performed in this study. The object of the first experiments was to examine experimentally the appraisal of TYLER and GEAKE (I96I) on the relationship between shell weight per unit of surface area and percentage of shell in eggs of different sizes laid by young and old hens. Subsequently shell weight per unit of surface area was compared with breaking strength and shell thickness of eggs laid by young hens only.

\section{MATERIALS AND ME'THODS}

\section{Experiment 1}

Sixty-four S. C. White Leghorn hens were used ; 32 were Io months old and the rest, in their second laying year, about 22 months of age. The birds were individually caged, and fed a commercial laying mash ad libitum. A total of 1024 eggs were collected (612 from the young flock, average weight $53 . \mathrm{Ig}, \mathrm{S}$. E. $=0.7$; and $4 \mathrm{I} 2$ from the older one, averaging $64.2 \mathrm{~g}, \mathrm{~S}$. E. $=0.4$ ) during four weeks. Each egg was weighed and tested according to the following criteria :

a) Shell weight per unit of surface area. - The contents of the eggs were emptied, the shell was thoroughly washed in running water, dried for two hours at $105^{\circ} \mathrm{C}$ with the shell membranes intact, and weighed on an analytical scale to the nearest $0.0 \mathrm{I}$. Shell weight per unit of surface area was calculated according to the formula of MUELLER and Scotr (1940) for the surface area of the egg.

b) Percentage of shell. - This was calculated as shell weight $\times 100 /$ whole egg weight.

\section{Experiment 2}

Two hundred and ninety-five eggs obtained from zo nine-month old S. C. White Leghorn hens over a period of three weeks were used in this experiment (average egg weight $55.6 \mathrm{~g}$, S. E. \pm I.4). Birds were kept under the same conditions as in Experiment $\mathrm{I}$ and tested according to the following criteria :

a) Breaking strength. - Measurements were carried out as described by MeHring (I949). In order to achieve better stability of the measuring instrument, its movable parts were made from stainless steel instead of from wooc. The applied breaking force was measured to the nearcst gram. The position of the egg when measured was kept as described by Hurwitz and Griminger (I962).

b) Shell weight per unit of surface area. - The same procedure as described in Experiment I.

c) Shell thickness. - 'This was measured by an Ames Thickness Measure micrometer, with an accuracy of $0.005 \mathrm{~mm}$. Five repeated measurements were taken at the broad and the narrow poles and at the equator of each shell. Shell thickness was designated as the arithmetic average of the five measurements. In order to eliminate crrors due to the natural curvature of the shell, pieces of $2-3 \mathrm{~mm}^{2}$ were measured.

The statistical analysis of the data obtained was carried out by calculating correlation coefficients and regression equations according to SNEDECOR (1956). 


\section{RESUITS AND DISCUSSION}

\section{Experiment 1}

Figure I presents the graphical scattering of the relationship between egg-shell weight per unit of surface area and the percentage of shell from the whole egg weight, in both young land old chickens. Each dot represents the average values of the

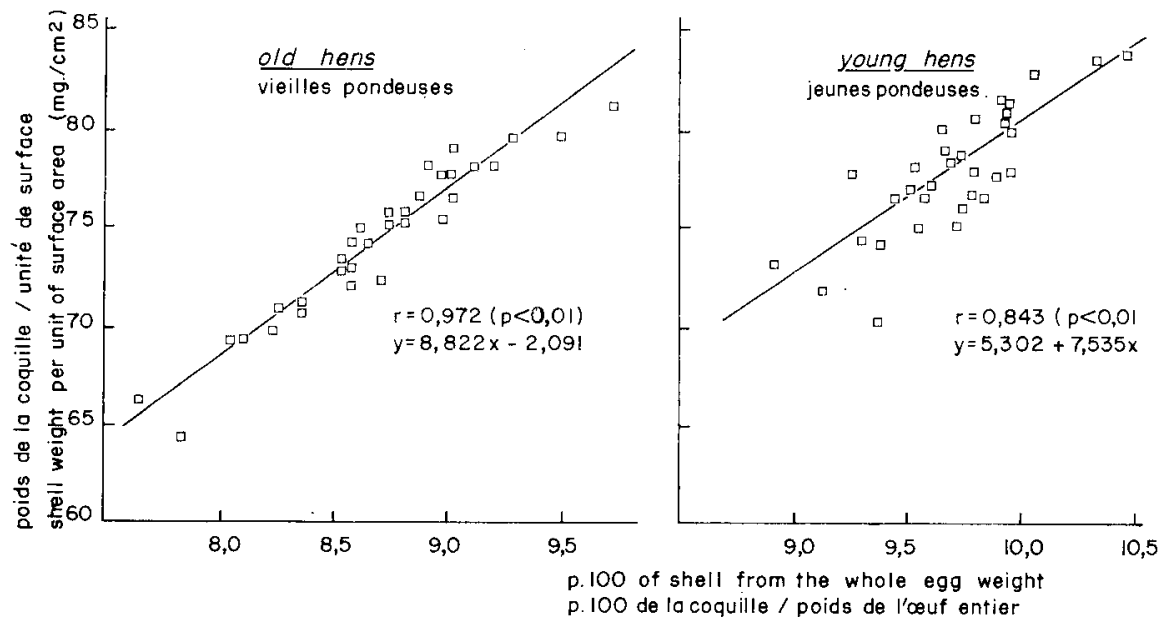

FrG. I. - Graphical scattering of the relationship between shell weight per unit of surface area and the percentage of shell from the whole egg weight in young and old hens.

Relation entre le poids de la coquille par unité de surface et le pourcentage de la coquille par rapport au poids de l'cuf entier chez les jeunes et les vieilles pondeuses.

2 criteria obtained from the total number of eggs laid by each individual. hen. Although the calculated correlation coefficient between the two criteria was highly significant in both groups $(<\mathrm{o} . \mathrm{Or}$ ), it was much higher for the old birds. As seen from the figure, the scattering of the average values near the regression line is more widely spread amongst the young birds than amongst the old ones. This tendency might be explained by the higher variability in egg size at this age (higher S. E. than in the old group).

Figures 2 and 3 respectively present distribution of shell weight per unit of surface area and percentage of shell, of both groups, as a percentage of total eggs sampled. The figures show that when percentage of shell is used as a criterion for evaluating egg-shell quality, two peaks are reached, for young and old birds separately. Most of the columns in the young group present higher percentage of shell values than those in the old group. However, when shell weight per unit of surface area between the groups is compared (fig. 2), a clear tendency of overlapping columns is seen. Asmundson and BAKER (I940) were the first to investigate the influence of egg volume and shell thickness on percentage of shell. They concluded that percentage of shell may not be a satisfactory measure of shell quality when comparing eggs of 
different species if shell thickness varies significantly. They also showed mathematically, assuming the egg to be a perfect prolate spheroid, that for any given shell thickness, percentage of shell will decrease in egg volume. HURwiTZ and GrImiNGER also criticised the percentage of shell method (I962). In the present experiment, in

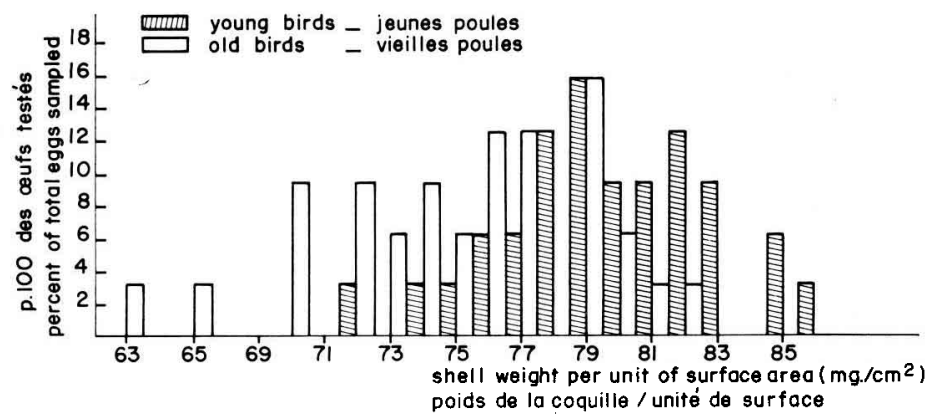

FIG. 2. - Shell weight per unit of surface area as percent of total eggs sampled, in young and old birds

Poids de la coquille par unité de surface en fonction du pourcentage d'oufs testés chez les jeunes et vieilles poules

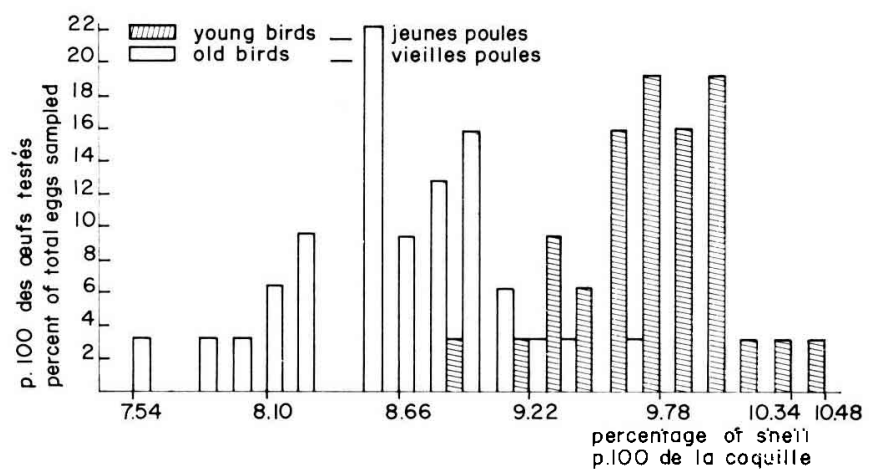

FIG. 3. - Percentage of shell from the whole egg weight as percent of total eggs sampled, in young and old birds.

Pourcentage de la coquille par rapport au poids de l'cuf entier en fonction du pourcentage d'cuts testés chez les jeunes et vieilles pondeuses

which two groups of birds of different age and having eggs markedly different in size (64.2 $\mathrm{g}$ and 53. I $\mathrm{g}$ for old and young hens, respectively) were compared, it was possible to prove that, with increase and stabilization of egg size following aging of the birds, the values of percentage of shell in eggs of older hens was much lower than in eggs of young hens. These differences between the two groups were not so pronounced when shell weight per unit of surface area was used as a measurement. Statistical analysis using the " $t$ ) test showed significantly higher mean values for the young group of birds in both methods. However, the " $t$ " values obtained from the 2 methods differed sharply from each other : Io. 6 for percentage of shell, and 3.8 for shell weight per unit of surface area. It is suggested that percentage of shell may still be used as a method of evaluating egg shell quality, provided eggs of nearly equal sizes are compared. 


\section{Experiment 2}

Figure 4 represents the graphical scattering of the relationship between eggshell thickness and breaking strength of the total eggs laid by each individual hen used in the experiment. Since the calculated standard error of the average measu-

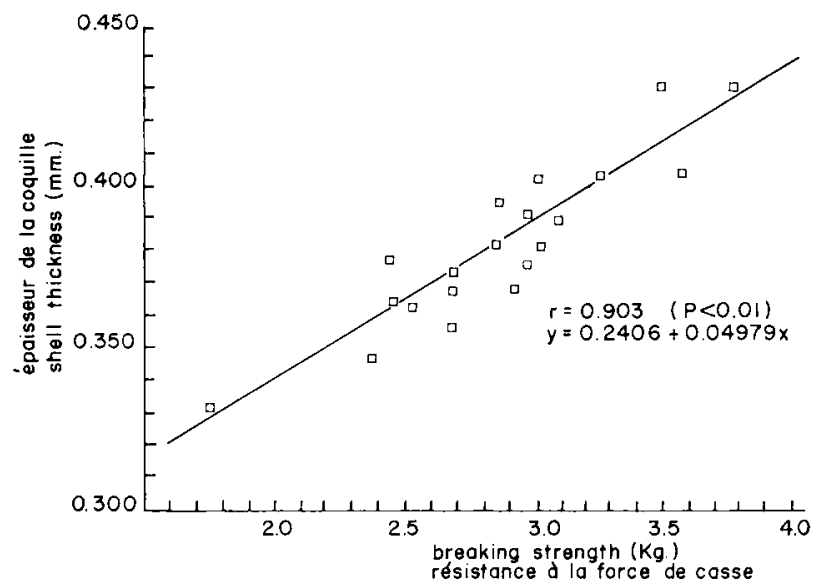

FIG. 4. - Graphical scattering of the relationship between egg shell thickness and breaking strength Relation entre l'épaisseur de la coquille d'ceuf et la résistance à la force de casse

rements of the eggs of each hen was low (ranging from 0.093 to $0.150 \mathrm{~kg}$ for the breaking strength, and 0,003 to $0.010 \mathrm{~mm}$ for the shell thickness), it was possible to use the average measurements per hen in this figure. (This claim can also be applied for Experiment $\mathrm{I}$.) The figure shows a highly significant correlation between the two parameters measured $(r=0.903, \mathrm{P}<0.0 \mathrm{I})$.

The relationship between breaking strength of the shell and shell weight per unit of surface area presented in fig. 5 indicates a highly significant correlation between these two parameters $(r=0.8 \mathrm{I} 2, \mathrm{P}<0.0 \mathrm{I})$, although lower than that obtained between shell thickness and breaking strength. Fig. 6 demonstrates the graphic

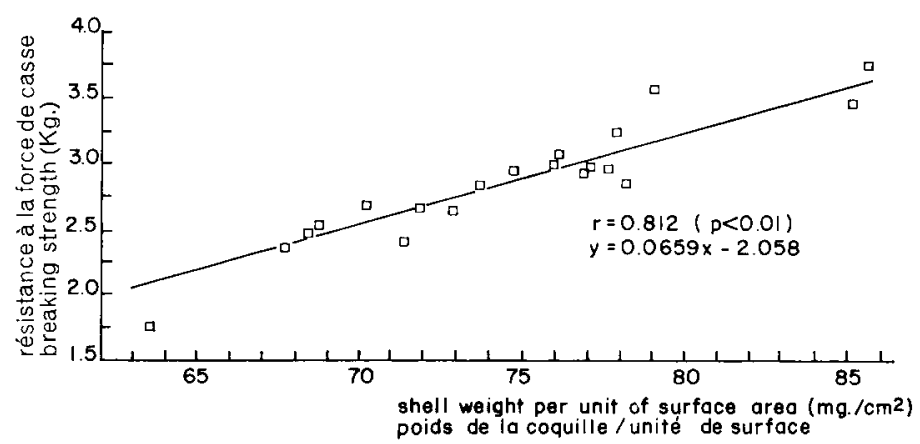

FIG. 5. - Graphical scattering of the relationship between breaking strength and shell weight per unit of surface area Relation entre la résistance à la force de casse et le poids de la coquille par unité de surface 
distribution of the correlation between egg-shell thickness and shell weight per unit of surface area. The calculated coefficient of correlation between these two characteristics was found to be higher than the other two coefficients $(r=0.925, \mathrm{P}<0 . \mathrm{OI})$. The standard error of shell weight per unit of surface area calculated was between 0.6 and $2.1 \mathrm{mg} / \mathrm{cm}^{2}$ for the total number of eggs of each individual hen.

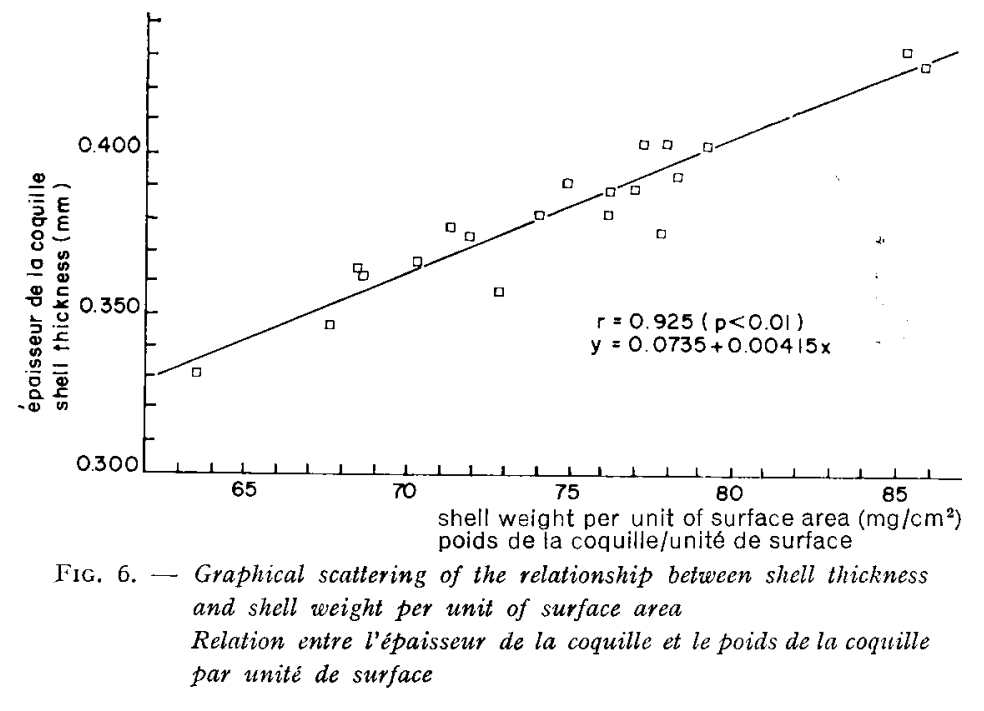

Although shell thickness is not always a suitable criterion for measuring breaking strength, since factors such as shell texture and density are involved (TYLER and GEAKE, I958 ; RAUCH, I959), other workers have found a highly significant correlation between these parameters (GODFREY and JAAP I949; BROOKS and HALE, I955; RAUCH, I959). The correlation coefficient value between shell thickness and shell weight per unit of surface area obtained in this experiment $(r=0.925)$ is in close agreement with the coefficient reported by TYLER and GEAKE (I96I), and is sufficiently accurate for general routine work. Shell weight per unit of surface area as a criterion of evaluating shell quality seems to have some advantages over the other methods mentioned. The accuracy of this measurement is higher and more objective than thickness measurements. Furthermore, this procedure facilitates evaluation of larger quantities of eggs in a short time for research purposes.

Reçu pour publication en octobre 1969.

\section{SUMMARY}

A comparison between percentage of shell and shell weight per unit of surface area was performed in eggs (53.I $\pm 0.7 \mathrm{~g} \mathrm{av}$. weight) laid by ro-month old $\mathrm{S}$. C. White Leghorn hens and in eggs $(64.2 \pm 0,4 \mathrm{~g}$ av. weight) of 22 -month old hens of the same breed. A highly significant correlation was found between the two methods in both groups. " $t$ " tests for significance of the difference between the two groups showed significantly higher mean values for the young group of birds in both methods. However, the " $t$ " values were 10.6 for the percentage of shell and 
3.8 for shell weight per unit of surface area. Since percentage of shell is strongly correlated with egg size, it is suggested that it may be used as a criterion for evaluating egg shell quality when eggs of nearly equal size only are compared. In a second experiment, breaking strength, egg shell thickness and shell weight per unit of surface area were compared in eggs $(55.6 \pm$ I. $4 \mathrm{~g})$ of ninemonth old birds. Highly significant correlations were found between the methods studied. Shell weight per unit of surface area was found to be more objective and therefore the method of choice for the subsequent studies.

\section{REFERENCFS}

Asmundson V.S., Baker G. A, r940. Percentage of shell as a function of shell thickness, egg volume and egg shape. Poultry Sci., 19, 227-232.

BAKER R. C., Curtis R., r958. Strain differences in egg-shell mottling, internal quality, shell thickness, specific gravity and the interrelationships between these factors. Poultry Sci., 37, ro86-Iogo.

Brooks J., Hale H. P., 1955. Strength of the shell of the hen's egg. Nature, Lond., 175, 848-849.

Carter T, C., I968. The hen's egg: (a) density of egg shell and egg contents. Br. Poult. Sci., 9, 265-27r.

Carter T. C., Ig68. The hen's egg : $(b)$ estimation of egg mean and flock mean shell thickness. Br. Poult. Sci., 9, 343-357.

Fry J. L., Steet,e E. Ji., Rasplicka L. D., I963. 52nd Annual Meeting of the Poultry Association. Oklahoma State University, U. S. A.

GODFREY G. F., JAAP R. G., I949. The relationship of spccific gravity, I4 days incubation weight loss and egg shell color to hatchability and egg shell quality. Poultry Sci., 28, 874-889.

Hurwitz S., Griminger P., r962. Egg production and shell environment. Poultry Sci., 41, $499 \cdot 508$.

Marks H. L., Kinney T. B. Jr., Ig64. Measures of egg shell quality. Poultry Sci., 43, $269-27$ I.

Menring A. L., Jr., 1949. A device for measuring the strength of shells of eggs. Poultry Sci., 28,621-622.

Morgan C. L., I932. Relationship between breaking strength and the percent of egg shell. Poultry Sci, 11, I7I-I75.

Mueller C. D., Scott H. M., I940. The porosity of the egg shell in relation to hatchability. Poultry Sci., 19, I63-166.

OLsson N., r934. Studies on Specific gravity of hens' eggs. Otto Harrassowitz, Leipzig.

RAUch W., I959. Mathematics-statistische Beziehungen zwischen Eiqalitatsmerkmalen (Korrelationen und Regressionen). Arc. Gefluglk, 23, ro8-12I.

Romanoff A. L., I929. Studies on the physical properties of the hen's egg in relation to the function of shell-secretory glands. Biol. Bull., 56, 35I-356.

Schoorl P., Boersma H. Y., 1963. Research on the quality of the egg shell. 12th World's Poully Congress, Sidney, 432-435.

Snedecor G. W., I956. Statistical Methods, Iowa State University Press, Ames, Iowa, U. S. A.

Tung M. A., Staly L. M., Richards J. F., I968. Studies on egg shell strength, shell stiffness, shell quantity, egg size and shape. Br. Poult. Sci., 9, $221-229$.

Trler C., Geake F. H., I958. Studies on egg shells. IX. The influence of individuality, breed and season on certain characteristics of egg shells from pullets. J. Sci. Fd. A gric., 9, 473-483.

Tyler C., Geake F. H., Ig6I. Studies on egg shells. XV. Critical appraisal of various methods of assessing shell thickness. J. Sci. Fd. Agric., 4, 281-289. 